DOI: $10.17058 /$ redes.v20i3.3655

\title{
O PATRIMÔNIO LOCAL COMO UM FATOR DE DESENVOLVIMENTO: POTENCIALIDADES TURÍSTICAS DE JAGUARÃO-RS
}

\section{THE LOCAL HERITAGE AS A FACTOR OF \\ DEVELOPMENT: \\ TOURISM POTENTIAL JAGUARÃO-RS}

\author{
Juliane Conceição Primon Serres \\ Universidade Federal de Pelotas - Pelotas - RS - Brasil
}

Juliana Rose Jasper

Universidade Federal do Pampa/Campus Jaguarão - Jaguarão - RS - Brasil

\begin{abstract}
Resumo: O patrimônio local é um elemento de identidade e, atualmente, vem se convertendo em um importante componente de motivação para o turismo. Tendo em vista seu centro urbano, avaliado como maior conjunto histórico e paisagístico protegido no Rio Grande do Sul, a cidade de Jaguarão, localizada no Sul do estado, município limítrofe Brasil e Uruguai, foi considerada pelo Instituto do Patrimônio Histórico e Artístico Nacional-IPHAN, Patrimônio Cultural Brasileiro desde 2011. O texto discute as possibilidades do aproveitamento do patrimônio de Jaguarão como uma alternativa para o turismo e o desenvolvimento local.
\end{abstract}

Palavras-Chave: Patrimônio. Desenvolvimento. Turismo. Jaguarão.

Abstract: The local heritage is an identity element and it is currently becoming an important component of motivation for the tourism. Given its urban center, pointed as the largest protected area under the historic and landscaped perspective of the Rio Grande do Sul, the city of Jaguarão, located in the southern part of the state, a municipality bordering Brazil and Uruguay, was considered by IPHAN (Institute of National Historical and Artistic Heritage) Brazilian Cultural Heritage since 2011. The paper discusses the possibilities of taking the heritage of Jaguarão as an alternative for tourism and local development.

Keywords: Heritage. Development. Tourism. Jaguarão.

\section{INTRODUÇÃO}


O Município de Jaguarão está localizado no Sul do Estado do Rio Grande Sul, na fronteira do Brasil com o Uruguai, fundado como um local de defesa militar da fronteira. Em 1832, foi elevado a Vila e, em 1855 , à condição de cidade. Jaguarão viveu seu apogeu econômico como outras cidades do entorno - até as últimas décadas do século XIX. Com o fim da escravidão e, por conseguinte, da principal atividade econômica da região - a criação, exportação, comércio (e contrabando) de gado-, a cidade passou a viver, lentamente, um período de declínio econômico.

Do período de crescimento econômico, a cidade herdou uma arquitetura imponente. Foram construídos muitos casarões - os fazendeiros tinham casas na cidade-, bem como edifícios de uso comercial, como o mercado público, matadouro público, cadeia, além de igrejas, teatro, cemitério e clubes sociais. As primeiras construções poucas - ainda datam do período Colonial, mas, em sua maioria, são do Império e das primeiras décadas da República.

O período áureo da urbanização da cidade, segundo Martins (2001), data das décadas entre 1870 e 1910, quando a cidade recuperou seu crescimento econômico - depois de crises políticas e guerras. Segundo Franco (1980), ao final do século XIX, Jaguarão era um pequeno núcleo urbano pré-industrial, com cerca de mil casas e população de aproximadamente dez mil moradores e um comércio próspero.

O código de postura de 1870 já apresentava um projeto de cidade, definia a demarcação das ruas, o volume e orientação das casas, entre outros. Esses princípios baseavam-se na necessidade de salubridade, mas as escolhas estilísticas das construções baseavam-se na estética predominante no período: o estilo eclético. $O$ ecletismo encontrado nas construções da cidade revela uma adaptação local da arquitetura predominante no continente europeu (OLIVEIRA, 1988), marcado pela mescla de uma série de elementos arquitetônicos de diversos períodos. O "embelezamento" da cidade expresso em um novo código de posturas de 1898, segundo Miranda (2002), apresentava uma nova estética, representativa do novo momento político, o positivismo- 
republicano, que buscava se desvencilhar da imagem de cidade colonial por meio do ordenamento e desenvolvimento das cidades. ${ }^{1}$

Os recursos econômicos, preocupações estéticas e uma certa homogeneidade construtiva, bem como a estagnação econômica das décadas seguintes, legaram a Jaguarão um conjunto arquitetônico harmônico, reconhecido nas últimas décadas pelo valor patrimonial. Em 2011, o IPHAN tombou o seu centro urbano avaliado como maior conjunto histórico e paisagístico protegido no Rio Grande do Sul, além da Ponte Internacional Mauá, construída na década de 1930, entre as cidades de Jaguarão, no Brasil e Rio Branco, no Uruguai, primeiro tombamento de um bem binacional.

Este artigo tem por objetivo discutir algumas questões referentes ao patrimônio e apresentar a possibilidade do aproveitamento do patrimônio de Jaguarão como uma alternativa de turismo e de desenvolvimento local, visto, não necessariamente, como crescimento econômico, mas sim como melhora da qualidade de vida da população.

\section{A CONSTRUÇÃO DA CATEGORIA PATRIMONIAL}

O patrimônio, como um tema emergente de caráter essencialmente interdisciplinar, promove debates em vários campos, nos quais se evidenciam, seu valor social, econômico, histórico e identitário. Choay (2006, p.11) define patrimônio como um conceito nômade, adjetivado por várias designações, de acordo com diferentes critérios. Pela tipologia, pode-se nominar patrimônio artístico, histórico, cultural; pela a cronologia, antigo, moderno, contemporâneo; segundo a geografia, mundial, regional, local. É um conceito muito extenso. Ao patrimônio, estão associados bens materiais e imateriais. Independente de suas especificidades, é certo que o patrimônio é uma construção cultural: cada cultura define seus referentes patrimoniais e, como tal, sujeita a circunstâncias históricas e sociais (BALLART; TRESSERAS, 2007). Sendo assim, o patrimônio deve ser analisado segundo cada período e sociedade.

Mas afinal, de que se trata quando se refere a patrimônio? A resposta não é simples e foge dos propósitos deste texto adentrar por

\footnotetext{
1 Os três códigos de Posturas Municipais, em 1870, em 1898 e em 1948, sendo que este último delimitou o perímetro urbano.
} 
todas as ramificações deste debate, mas alguns elementos são importantes para a discussão que se quer empreender. A premissa básica é de que a pergunta só pode ser respondida segundo um(s) contexto(s), ou historicamente, se esta for a opção. Cada sociedade elege seus patrimônios, aqueles elementos que as identificam, ou com os quais querem identificar-se, uma vez que o patrimônio é sempre uma construção.

O patrimônio está associado a uma ideia de continuidade, ele conecta, relaciona os seres humanos, é um elemento de transmissão cultural (BALLART; TRESSERAS, 2007, p. 12) e, como tal, tem existência antiga, embora a ideia de preservação e transmissão seja relativamente recente. A moderna preservação do patrimônio inicia na França, no período posterior a Revolução, quando os monumentos nacionais estavam sob o risco do desaparecimento.

Se o patrimônio não é dado, mas construído historicamente, como ele é construído? Quem seleciona, dentre o mundo natural e cultural, o que deve ser preservado e transmitido?

Em primeiro lugar, ainda que tenha referências na realidade, o patrimônio é construído discursivamente. Um conjunto de ideias e imagens são mobilizadas para justificar as escolhas patrimoniais para, então, construírem-se discursos que legitimem essas escolhas. Esses mecanismos são complexos. Ballart e Tresseras (2007) colocam a questão sobre quais os elementos mais importantes, representativos e ricos em possibilidades de uso, segundo os critérios de cada momento histórico - pode-se dizer, que elementos culturais - merecem ser salvos e transmitidos? Esses autores mencionam dois aspectos, alguns envolvidos nas escolhas patrimoniais.

O primeiro aspecto refere-se aos contextos de seleção. São pessoas e instituições responsáveis por estas escolhas, porém, estes agentes estão condicionados por contextos científico-profissionais, político-administrativos e econômicos. O segundo aspecto refere-se a valores. Para a seleção do que se considera patrimônio, tem-se quatro grandes grupos de valores: os simbólicos, os estéticos ou formais, os econômicos, também chamados de valor de uso e os informativocientíficos, entre esses destaca-se o valor histórico. A partir de algum desses critérios, se constroem-se discursos que justifiquem as escolhas patrimoniais. Geralmente, a ameaça da perda mobiliza esses discursos, 
seja em nível local ou internacional, contemporaneamente, por meio de órgãos supranacionais como a Unesco.

Prats (2005) distingue patrimônio local e patrimônio localizado. O primeiro seria quase um "não patrimônio", composto por todos os objetos, lugares e manifestações de escasso interesse para além da comunidade, em maior ou menor grau, toda a sociedade o possui. Já o patrimônio localizado provoca interesse por si mesmo, também forma parte do patrimônio local, mas se distingue desse, entre outros, por atingir um maior número de interessados. A premissa básica em qualquer um dos casos é de que o patrimônio deve ser reconhecido para haver a preservação.

A patrimonialização em nível local apresenta um potencial de reflexibilidade e complexidade maior que em qualquer outro nível, uma vez que há o envolvimento maior dos interessados. Ainda que os poderes locais sejam os responsáveis pela "ativação patrimonial", estes se veem forçados a refletir as sensibilidades maioritárias da população, quanto maior o consenso, maior a legitimação e consequente preservação patrimonial (PRATS, 2005).

Entretanto, como uma construção, envolvendo um conjunto cada vez mais complexo de interesses e atores, o patrimônio, sobretudo o local, é um campo de disputas e conflitos, os quais não se pode perder de vista nos processos de seleção, preservação e usos do patrimônio, que é sempre plural. Nesse sentido, é necessário desenvolver uma crítica patrimonial que esteja, especialmente, centrada nos conteúdos, nos discursos, nos projetos, intervenções e políticas patrimoniais (PRATS, 2005).

Quanto ao uso, as questões são ainda mais instigantes. Ao relacionar patrimônio e turismo, Prats (2011) diz que existem projetos patrimoniais de caráter local que não tem, necessariamente, uma orientação turística, mesmo que a associação entre turismo, patrimônio e desenvolvimento local encontre-se estendida, ou seja, o patrimônio não nasce associado ao turismo, embora seja, atualmente, um de seus principais desdobramentos.

\section{A CIDADE DE JAGUARÃO E SEU PATRIMÔNIO HISTÓRICO}


Jaguarão localiza-se no extremo meridional do Brasil, a uma distância de $380 \mathrm{Km}$ da capital do Rio Grande do Sul, Porto Alegre, e faz fronteira com a cidade de Rio Branco no Uruguai. O município possui uma população de, aproximadamente, 28 mil habitantes, um Produto Interno Bruto-PIB de 452. 814 mil reais (IBGE, 2012) e um Índice de Desenvolvimento Humano - IDH de 0,707 (Atlas Brasil, Programa das Nações Unidas para o Desenvolvimento, 2013). A cidade faz parte do Conselho Regional de Desenvolvimento da Região Sul-COREDE Sul. Como distrito, foi criada em 1812, com o nome de Divino Espírito Santo do Cerrito. Em 1832, foi elevada à condição de vila e, em 1855, tornouse cidade com o nome de Jaguarão. ${ }^{2}$

O núcleo urbano de Jaguarão foi tombado no ano de 2011 , pelo IPHAN, mas, mesmo antes desse reconhecimento nacional, o estado, por meio do Instituto do Patrimônio Histórico e Artístico do Estado-IPHAE e o município, por meio da Lei de Proteção de Preservação do Patrimônio Histórico Arquitetônico Turístico de Jaguarão - PPHAT (Lei n. 4.682 de 19 de dezembro de 2007), haviam reconhecido a importância histórica e arquitetônica do centro urbano da cidade, e de algumas de suas edificações. Os centros históricos são um tema de intenso debate nas últimas décadas, uma das razões seria o crescente deterioro, outra, a formação de uma consciência para a conservação (CARRIÓN, 2001).

$\mathrm{Na}$ década de 1980, iniciou-se uma preocupação em identificar inventariar - o patrimônio arquitetônico da cidade, primeiro por meio do projeto Jaguar (1982), um estudo desenvolvido em parceria entre a prefeitura municipal, o IPHAN e a Faculdade de Arquitetura da Universidade Federal de Pelotas. O projeto foi uma das primeiras iniciativas nesse sentido, juntamente com o Projeto de Inventário do Patrimônio de Jaguarão, realizado em 1987. Esses dois projetos ofereceram elementos para a elaboração do Programa de Revitalização Integrada de Jaguarão-PRIJ, que visava determinar uma série de instrumentos urbanísticos, bem como critérios de análise do acervo arquitetônico inventariado, além de estabelecer orientações para as futuras obras de conservação e intervenção nas zonas de preservação (OLIVEIRA; SEIBT, 2005). Pelo Projeto, a área urbana do município foi dividida em Zona de Preservação Histórica Arquitetônica-ZPHA e Zona de Preservação Histórica Natural - ZPHN. Esses projetos, que traziam em

\footnotetext{
2 Fonte: http://biblioteca.ibge.gov.br/visualizacao/dtbs/riograndedosul/jaguarao.pdf
} 
seu bojo discussões sobre a utilização do patrimônio, serviram como referência para as ações posteriores, tanto para a Lei n. 4.682 de 19 de dezembro de 2007 quanto para a instituição do Tombamento.

Ao analisar-se o PRIJ, percebe-se a incorporação das discussões presentes em vários documentos internacionais de preservação, como a Carta de Veneza (1964), que dizia que os monumentos - das grandes criações até as criações modestas - ofereciam testemunhos de uma civilização particular, bem como, sua conservação deveria ter destinação útil à sociedade, ou a própria Carta de Restauro (1972) que, ao referirse à tutela dos centros históricos, previa que estes deveriam ser preservados por seu valor como testemunho, documentos de cultura urbana, independente de seu valor artístico ou formal. Todos os valores urbanísticos, arquitetônicos, ambientais, tipológicos e construtivos, deveriam ser considerados através de uma atenta leitura históricocrítica.

O PRIJ e o Projeto Jaguar foram as bases para a PPHAT que prevê:

I. Promover e incentivar a conservação, preservação e revitalização dos bens de valor histórico, arquitetônico, paisagístico e turístico; II. Compatibilizar o uso e ocupação do solo com a proteção do ambiente construído nas áreas de preservação; III. Implantar estratégias de preservação como incentivos fiscais e tributários; IV. Valorizar a memória da cidade através de programas de educação e conscientização da preservação do patrimônio cultural nos estabelecimentos de ensino no município; V. Proporcionar subsídios para a realização de convênios com órgãos estaduais e federais; VI. Promover a sensibilização da comunidade na conservação cultural do município.

As medidas de preservação adotadas na cidade referem-se, essencialmente, à preservação, do ponto de vista formal, das características arquitetônicas, históricas e paisagísticas. Menciona en passim o interesse em valorizar a memória e promover educação e conscientização da população.

Nessas últimas décadas do século $X X$, devido ao crescimento urbano, segundo Gutman (2001), os centros históricos passaram a ser alvo de atenção. Passaram a ser estudados de maneira integral, em suas múltiplas dimensões, urbanas e patrimoniais e, em várias cidades da 
América Latina, foram promovidos planos estratégicos de gestão das cidades.

Em 2009, o Município de Jaguarão foi contemplado com o Projeto de Aceleração do Crecimento-PAC das Cidades Históricas e recebeu verbas do governo federal para aplicar em algumas obras, como a reabertura do Teatro Esperança e a elaboração do Dossiê de Tombamento do Conjunto Histórico e Paisagístico. Segundo o Ministério da Cultura (2009), esse programa tem por objetivo a requalificação dos sítios históricos, estimulando usos que possam gerar o desenvolvimento econômico, social e cultural do local. Por outro lado, propõe a melhoria na infraestrutura urbana e social.

Para instruir o Processo de Tombamento, foi realizado o cadastramento dos edifícios de interesse na área central de Jaguarão, compreendendo, aproximadamente, 124 quarteirões e 3.083 prédios, onde foram levantadas informações referentes à implantação, gabarito, linguagem arquitetônica, tipologia, usos, estados de caracterização e conservação dos imóveis. Das edificações estudadas, 627 foram elencadas como de interesse histórico ou cultural, além de propriedades rurais $^{3}$ (DOSSIÊ, 2011 , p. 156).

No Dossiê, que é um documento acima de tudo técnico, embora evidencie as justificativas históricas para a seleção dos bens a serem preservados, predominam os argumentos relacionados aos valores formais dos edifícios, embora esses não sejam vistos de forma isolada, mas em seu conjunto urbano. Ater-se-á um pouco em como foi descrito o patrimônio de Jaguarão. Ao fazer o levantamento, os técnicos se depararam com:

[...] um dos mais extensos e bem preservados conjuntos arquitetônicos do Brasil, que além do acervo eclético, conta com exemplares de várias linguagens arquitetônicas, representando as transformações decorrentes dos diversos

\footnotetext{
3 No Dossiê de Tombamento constam, ainda, informações sobre as propriedades rurais: nos edifícios construídos nessas propriedades, observa-se a predominância de edificações com linguagem luso-brasileira, e mesmo as intervenções sofridas (atuais e mais antigas) tendem a reforçar a representação do período colonial através da adoção da linguagem neocolonial. In: $O$ avanço da fronteira meridional. Dossiê de Tombamento Conjunto histórico e paisagístico de Jaguarão - RS. Org. Anna Finger. Revisão: Ana Lúcia Meira. IPHAN, 2010.
} 
períodos históricos e econômicos pelos quais a cidade passou. Os exemplares mais significativos se localizam, em sua maioria, na área formada pelo tecido mais antigo, com alguns exemplares isolados em seu entorno. (DOSSIÊ, 2010, p. 159).

A cidade não foi construída em um único momento. As edificações registram as distintas épocas de construção e ocupação dos espaços. Além dos edifícios de estilo eclético mencionados, pode-se encontrar, na cidade, outras linguagens arquitetônicas que estão mais ou menos "zoneadas" de acordo com o crescimento da cidade. Os inventários realizados identificaram linguagens: luso-brasileira, eclética do século $X I X$, eclética do século XX, eclética simplificada, neocolonial, protomoderna, vernacular, modernista, contemporânea e indefinidas (DOSSIÊ, 2010, p. 160-162). A cidade, nesse sentido, pode ser lida como um documento que registra os distintos momentos de sua construção. Conforme Carrión (2001), a cidade é um espaço plutitemporal.

Para fins de tombamento, a cidade foi dividida em dez setores (Figura 1), sendo que, para os setores do 1 ao 4 , devido à presença de bens de relevância do ponto de vista formal e histórico, recomendou-se o tombamento. Os demais foram delimitados como área de proteção do entorno (Figura 2), que devem ser preservadas para não desfigurar o conjunto e permitir uma leitura da história da cidade.

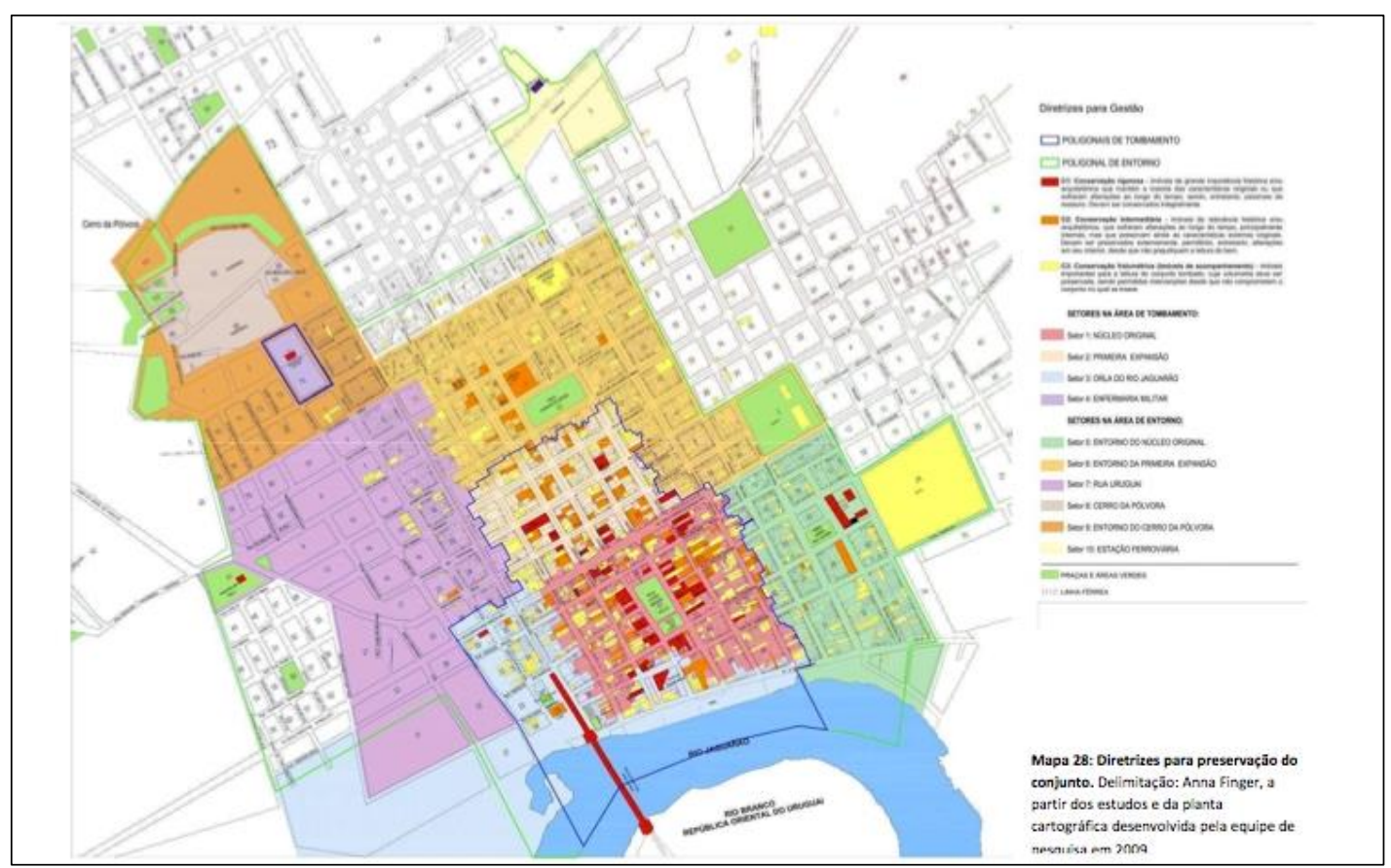

Figura 1: Mapeamento dos Setores da cidade.

Fonte: Dossiê do Tombamento, 2010. 


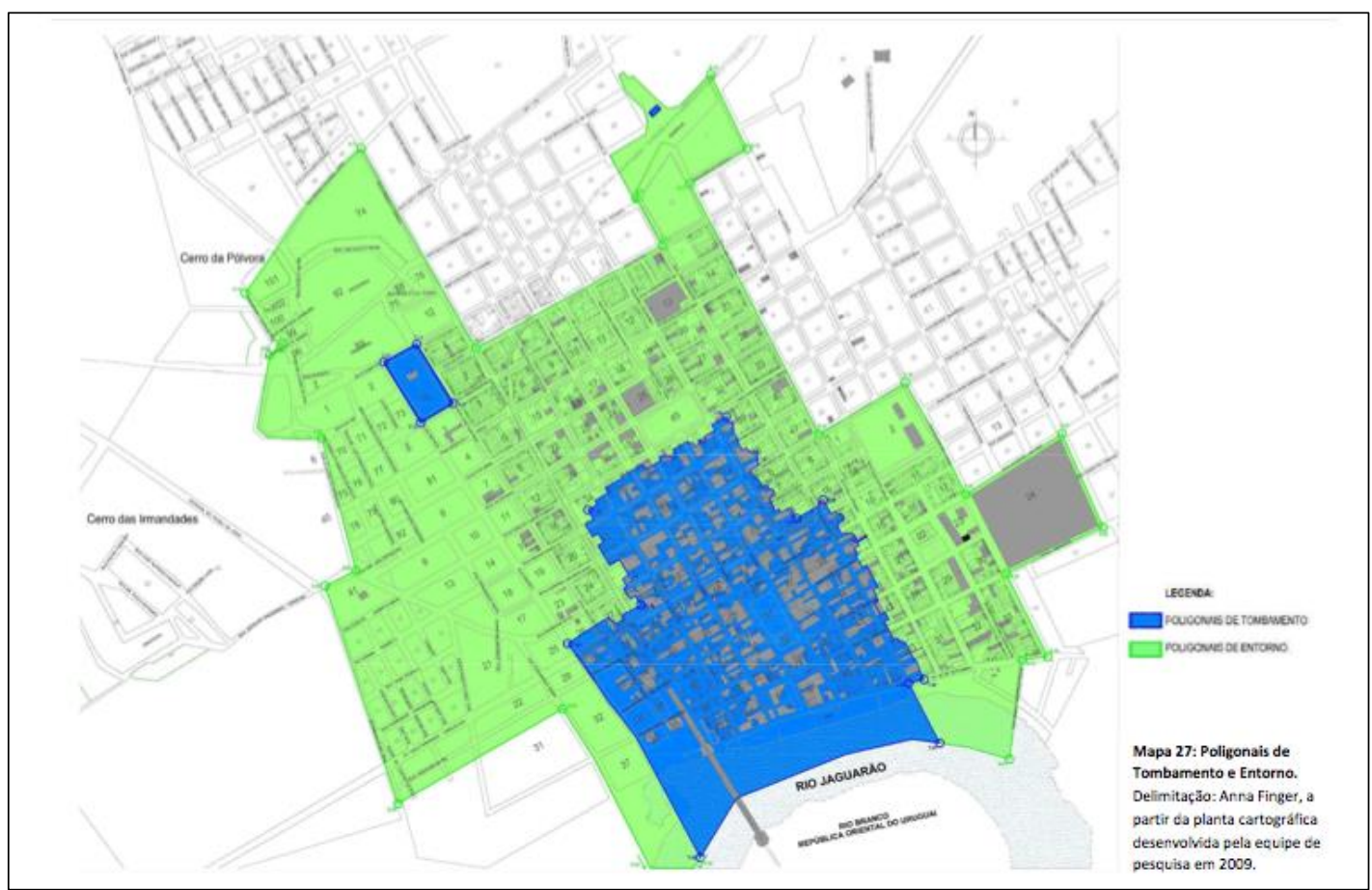

Figura 2: Mapeamento da área do tombamento (azul) e entorno (verde).

Fonte: Dossiê do Tombamento, 2010.

Os setores mapeados para o tombamento foram: o Núcleo Original, onde inicia o processo de urbanização da cidade (Setor 1), com predominância do estilo eclético do XIX, com destaque para a Igreja Matriz do Divino Espírito Santo, o Antigo Fórum (Casa de Cultura); a Primeira Expansão Urbana (Setor 2), iniciada por volta de 1846, com o predomínio do eclético do século $\mathrm{XX}$, com destaque para Teatro Esperança; Casa Carlos Barbosa (Eclética XIX), Igreja Imaculada Conceição; a Orla do Rio Jaguarão (Setor 3), composto pela Praça do Desembarque, predominam edifícios térreos, destacando-se os remanescentes da arquitetura luso-brasileira, eclético simplificado e arquitetura vernacular, são exemplos mais significativos, o Mercado Público, o Sobrado do Barão, a Ponte Mauá (neo-colonial) e, por fim, a área da Enfermaria Militar (Setor 4), que faz parte da primeira expansão urbana e tem como marco histórico as ruínas do prédio da Enfermaria Militar (Figura 3), construído no final do século XIX, com linguagem eclética, elemento de grande valor histórico e cultural para a cidade e região da platina do Rio Grande do Sul (DOSSIÊ, 2010, p.184-201). 


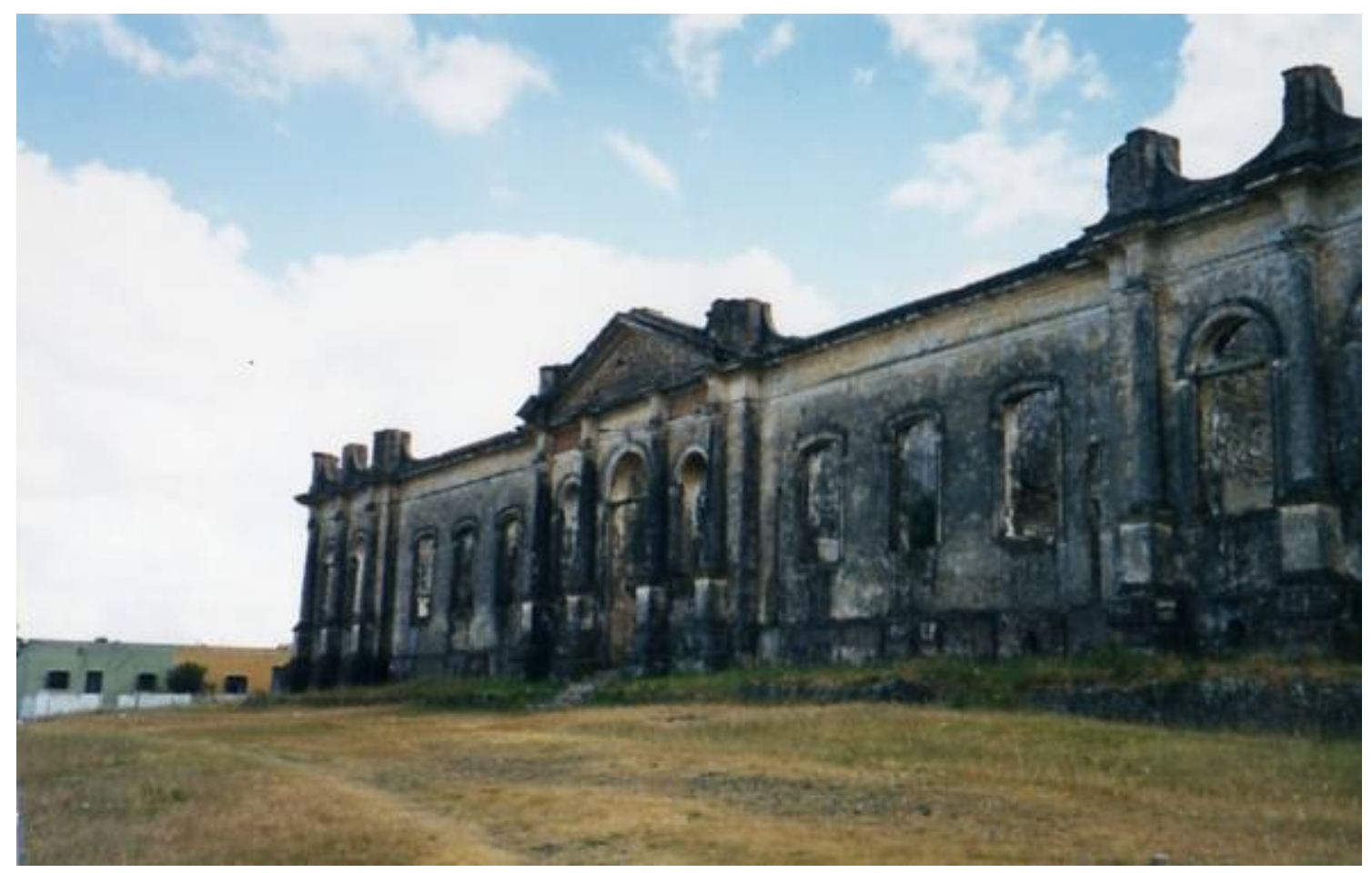

Figura 3: Ruinas da Enfermaria Militar.

Fonte: IPHAE. Processo de Tombamento: 47.068-19.00-SEC/86.

Os entornos desses setores também foram descritos e realizados os levantamentos sobre os bens mais significativos de cada setor. ${ }^{4}$

Apesar do conjunto urbano estar bem preservado, sobretudo ao redor da Praça Central Alcides Marques, encontram-se algumas desconfigurações. Alguns casarões foram substituídos por novas edificações a partir dos anos de 1970. É interessante perceber, pelos dados levantados no Dossiê, que podem ser facilmente constatados pelos moradores e visitantes da cidade, que o centro histórico de Jaguarão é formado por edificações residenciais $(65,2 \%)$, seguidas de edifícios comerciais e de prestação de serviços $(12,5 \%)$ e de uso misto (8\%) das construções (DOSSIÊ, 2010, p. 157).

O tombamento das edificações da cidade, devido à sua importância histórico-patrimonial, ocorre como uma tentativa de proteger esses bens da ameaça do deterioro e destruição. Entre essa

4 Para saber mais sobre os setores do entorno, do setor 5 ao 10, ver: Dossiê do Tombamento, 2010, p. 201 e seguintes. 
ameaças, está a desconfiguração lenta dos edifícios, uma vez que muitas dessas casas ainda mantêm seus usos e os proprietários buscam adaptá-las às dinâmicas da vida moderna. Assim, é comum ver abertura de garagens, portas, substituição de janelas, divisão de pavimentos, colocação de grades, entre outros. Antes de ser "patrimônio", as casas são as moradias dos habitantes.

Para efeitos de conservação do patrimônio, as edificações consideradas relevantes em Jaguarão foram classificadas em três grupos: as que requerem conservação rigorosa ( $\mathrm{C} 1$ ), imóveis de grande importância histórica e/ou arquitetônica, que ainda mantém a maioria das características originais; as de conservação intermediária (C2) para imóveis de relevância histórica e/ou arquitetônica que já sofreram alterações significativas, mas ainda preservam grande parte das características originais; conservação volumétrica (C3), imóveis importantes para a leitura do conjunto urbano, mas que não apresentam mais condições de autenticidade e/ou originalidade (Dossiê, 2010, p. 219-220).

A proteção patrimonial da cidade, conforme mencionado, foi promovida pelo valor formal das edificações, que devem ser lidas em seu conjunto, bem como pelo valor histórico da formação do Conjunto Histórico e Paisagístico, relacionados aos processos de expansão das ocupações portuguesa e espanhola no território e nas estratégias implementadas para garantir a posse desses territórios (DOSSIÊ, 2010, p. 175).

Essa situação de fronteira legou características urbanas e culturais distintas para Jaguarão, perceptíveis, por exemplo, desde os traçados viários retilíneos, característico das cidades espanholas, até o idioma próprio dessa região fronteiriça. Essas peculiaridades conferem uma singularidade e riqueza para o município.

Segundo Carrión (2001), os centros se configuram ao longo da história e não em um período acabado. Neles está inscrito o transcorrer do tempo, portanto, existe a necessidade de identificar as peculiaridades, construir a memória dos centros - para o nosso caso, centro urbano - considerando as distintas épocas e atores sociais.

De valor patrimonial muito significativo, como atestam os técnicos, desde a década de 1980, reforçado em 2011, com o tombamento em nível federal, a discussão que recém se inicia é sobre 
como esse patrimônio pode/deve ser apropriado pela comunidade. $\mathrm{Na}$ realidade, o Projeto Jaguar dos anos de 1980 já propunha essas discussões, mas não se tem como determinar a ressonância e alcance dessas discussões no período. A esse respeito, o Dossiê do Tombamento trata, basicamente, do patrimônio arquitetônico. Faz uma breve referência à necessidade da valorização do patrimônio edificado e das manifestações culturais que acontecem na região (Dossiê, 2010) e não vai além dessas orientações.

Porém, a revitalização urbana deve incluir não só a preservação de objetos arquitetônicos, mas também a preservação da paisagem urbana natural e deve contar com a participação de toda a comunidade, conforme se previa desde o PRIJ (OLIVEIRA, 2005). O patrimônio existe, segundo Carrión (2001), na medida em que um ou vários sujeitos o reconhecem, apropriam-se e o protegem como tal. Inicialmente, foram as elites cultas e, aos poucos, setores cada vez mais amplos da população foram dando lugar à apropriação social e democratização do patrimônio.

A preservação deve levar em consideração os distintos atores e os usos contemporâneos do patrimônio. A grande questão com a qual se defrontam os centros urbanos está em recuperar esses valores de uso e não apenas as fachadas dos imóveis, que podem levar a um simulacro patrimonial, um "fachadismo" vazio de sentidos, visto como um entrave para o desenvolvimento urbano.

Os centros históricos e áreas históricas devem ser vistos como parte viva e ativa das cidades, não como um conjunto monumental isolado. São unidades urbanas complexas, formada por múltiplas dimensões, físicas, culturais, econômicas, constituídas pela herança material, entorno natural, população com seus trabalhos, costumes, crenças e rituais (GUTMAN, 2001).

A importância da preservação está na necessidade de conservar e transmitir a memória da cidade. Nesse sentido, o patrimônio deve servir, em primeiro lugar, à comunidade local, seja para preservar ou construir sua identidade. $O$ patrimônio também pode gerar recursos econômicos de atividades como o turismo que, se bem planejado, pode ser um aliado da preservação.

Jaguarão, que hoje conta com pouco mais de 27 mil habitantes, tem procurado investir no turismo como uma atividade que possa trazer 
recursos para o município, gerar emprego e renda, além de ajudar a promover a conservação do patrimônio. $O$ turismo atualmente realizado em Jaguarão é basicamente de compras, com o destino a cidade uruguaia de Rio Branco, que concentra uma rede de Free-Shops. Poucos visitam a cidade por motivos culturais, como ver-se-á adiante.

O Conselho Internacional de Monumentos e Sítios - ICOMOS, em 1999, propunha que o turismo deve trazer benefício às comunidades residentes e lhes proporcionar meios e motivações para cuidarem e manterem seu patrimônio e práticas culturais. O município vê potencialidades no turismo cultural que pode advir do seu patrimônio.

\section{TURISMO E DESENVOLVIMENTO LOCAL}

O patrimônio é, atualmente, um importante componente de motivação para o turismo e desenvolvimento local. Ballart e Tresseras (2007) apontam alguns motivos para esse grande interesse pelo patrimônio, como a redescoberta do território, a explosão consumista e a cultura do ócio. A questão é que o patrimônio pode contribuir para o desenvolvimento, mais que econômico, social e cultural de uma localidade.

Depois de muita controvérsia em torno da categoria de desenvolvimento, como um conceito que tentava explicar as desigualdades sem considerar suas causas, atualmente, o discurso em torno do desenvolvimento compõe-se de uma rede de conceitos-chave tais como: riqueza-pobreza, produção-consumo, Estado-sociedade civil, igualdade-desigualdade e políticas públicas-privadas que precisam ser analisados para que se possa compreender o modelo de sociedade atual e agir para transformá-la. Nesse sentido, o desenvolvimento deve ser um processo multidimensional, territorial, ambiental, econômico, social e cultural (SILVA, 2000).

Quando se trata de identificar perspectivas para o desenvolvimento local a partir do patrimônio e turismo, refere-se a uma concepção abrangente de desenvolvimento, não apenas econômico, mas, sobretudo, social e humano. ${ }^{5}$ O desenvolvimento do qual se trata

\footnotetext{
5 Para a discussão sobre desenvolvimento ver: SFORZI, F. La economía marshalliana para explicar el Desarrollo. In: Manual de Desarrollo Local. FERMín, Rodríguez Gutiérrez. Coimbra: Gijón Ediciones Trea, S. L., 1999. SANTOS, Milton. Por uma outra
} 
deve ser pensado e planejado a longo prazo e com a interação da população local, tendo como finalidade a sustentabilidade. Magalhães (2002, p. 90) corrobora essa premissa no turismo, quando relata que:

[...] é preciso buscar o apoio da comunidade desde o início da organização territorial destinada a impulsionar o turismo. Sabe-se que é difícil, mas é possível, até imprescindível, para se alcançarem os resultados satisfatórios do desenvolvimento do turismo com base local.

O turismo cultural, com base no patrimônio de uma localidade, deve dar um retorno para essa comunidade Conforme Coriolano (2012), é necessário promover o turismo para benefício de comunidades, ou do desenvolvimento local, o que significa adotar políticas que criem oportunidades de trabalho e renda para a maioria.

Para o Ministério do Turismo (MTUR 2010), o turismo cultural compreende as atividades turísticas relacionadas à vivência do conjunto de elementos significativos do patrimônio histórico e cultural e dos eventos culturais, valorizando e promovendo os bens materiais e imateriais da cultura. Já segundo Moletta (2000), turismo cultural é o fluxo de turistas, cuja motivação para a viagem é o patrimônio, vinculado à cultura, à história e ao modo de viver de uma comunidade. Esse tipo de turismo pode ser realizado de duas formas. A tradicional, quando o turista visita os locais históricos, por meio da "compra do pacote"; a interativa: quando o turista interage com o local, procurando vivenciar o dia a dia da comunidade visitada.

O desenvolvimento do turismo cultural deve ser economicamente viável, social e ambientalmente sustentável. Dessa forma, vale lembrar que deve ter um planejamento e integrar ações do poder público, privado e comunidade. Assim como, deve preocupar-se em atender a demanda em relação à infraestrutura, serviços, preservação e manutenção dos atrativos culturais, além da criação de roteiros que permitam organizar melhor as visitas aos locais culturais, conforme Bahl (2004, p.31-32):

Globalização. Do pensamento único à consciência universal. Rio de Janeiro Record, 2000. 
[...] um roteiro turístico resume todo um processo de ordenação de elementos intervenientes na efetivação de uma viagem. $O$ roteiro pode estabelecer as diretrizes para desencadear a posterior circulação turística, seguindo determinados trajetos, criando fluxos e possibilitando um aproveitamento racional dos atrativos a visitar.

Nesse sentido, inicialmente é preciso identificar e avaliar no destino ou região os atrativos culturais significativos e com potencial para despertar o interesse e motivar o deslocamento do turista especialmente para conhecê-los. Os bens que integram o patrimônio constituem insumos básicos para o turismo. Na concepção de Prats (2005), formam o patrimônio localizado. Quanto maior a diversidade do patrimônio cultural, maiores serão as possibilidades de se criar produtos diferenciados, com mais opções e atividades, consequentemente, melhores serão as possibilidades para estimular o tempo de permanência do turista no destino.

Os procedimentos para a identificação dos atrativos culturais, de acordo com Ministério do Turismo (2010), envolvem uma pesquisa ordenada, que inclui o inventário detalhado com o descritivo das características e as possibilidades para o desenvolvimento de atividades turísticas, somando-se uma avaliação qualitativa e aspectos peculiares, que servirão, também, de suporte para a divulgação e promoção por agregar valor ao destino.

Um dos desafios para essa tarefa é justamente a compatibilização de linguagens, objetivos, modos de operação e de concepção sobre o Turismo Cultural. O Ministério do Turismo (2010, p.77) defende que "é preciso saber lidar com algumas críticas quanto ao incentivo a esse segmento, sobretudo às que se referem à possível transformação do patrimônio cultural em bem de consumo, o que poderia acarretar a perda de seu significado". Diante disso, o diálogo é a única forma de demonstrar os benefícios do Turismo Cultural responsável: as possibilidades de fortalecimento da cultura e da identidade cultural, despertando o orgulho nas comunidades, o resgate de manifestações culturais, a redescoberta da história dos lugares e a dinamização cultural da região. 
O Ministério do Turismo (2010) também ressalta que é necessário o estabelecimento de parcerias com os diversos agentes culturais do setor público e privado. Deve envolver, entre outros: Órgãos Oficiais de Cultura (Secretarias, Fundações, Diretorias); Órgãos Oficiais de Preservação do Patrimônio (IPHAN e Órgãos Estaduais e Municipais); Lideranças e atores locais, como Associações de Artesãos, Produtores Culturais, Artistas, Grupos Folclóricos, Mestres do Saber, etc; Gestores de Museus e Centros Culturais; Empresários do Setor Cultural; Órgãos de Planejamento e Obras Urbanas; Instituições de Ensino e Comunidade local. É a comunidade local que deve preservar e interpretar seus bens culturais e, assim, oferecer a verdadeira experiência turística cultural, traduzindo o sentido e o valor para quem visita uma determinada localidade.

A interpretação, associada aos princípios da educação para o patrimônio, serve para, além de informar, promover o diálogo sobre o valor e significados do patrimônio, estimulando, assim, uma relação de respeito e atitudes conscientes de conservação. Os variados meios e técnicas de interpretação do patrimônio visam sensibilizar o turista e enriquecer sua descoberta de forma criativa. É por isso que se diz que interpretar é "construir uma teia integrada de descobertas dos segredos e singularidades do atrativo" (MTUR, 2010, p.88). Portanto, para desenvolvimento turístico deve ser considerado a vocação do destino e o envolvimento da comunidade para que ela participe verdadeiramente do processo e possa usufruir de seus resultados.

Dessa forma o patrimônio, neste caso, o centro histórico de Jaguarão, pode, sem perder seus significados sócio-históricos e memória, ganhar novos usos e significados, que promovam o bom uso do patrimônio, tanto para a comunidade local quanto para os turistas.

\section{POTENCIALIDADES: A TíTULO DE CONSIDERAÇÕES FINAIS}

Pelo referido ao longo deste artigo, o patrimônio cultural de Jaguarão, uma vez que vem sendo reconhecido local e nacionalmente (IPHAN) e pela potencialidade turística como um fator de desenvolvimento local, apontar-se-á algumas iniciativas que vem sendo empreendidas nesse sentido.

Partindo do pressuposto que, para incentivar o turismo cultural, deve haver investimento, planejamento e políticas públicas que 
integrem ações do poder público, privado e comunidade, o patrimônio por si mesmo não gera desenvolvimento local, precisa ser ativado (PRATS, 2005) e o local com patrimônio deve preocupar-se em atender à demanda em relação à infraestrutura, serviços, preservação e manutenção dos atrativos culturais.

Em 2007, a PPHAT estabeleceu a proteção do patrimônio do município apontando para sua potencialidade turística. A lei previa a criação de instrumentos urbanísticos como o zoneamento, que delimitaria as áreas de preservação; regime de uso do solo, que estabeleceria as atividades da área, conforme as características das zonas; criação de índices urbanísticos, que regulamentaria a intensidade construtiva; e o estabelecimento de critérios de intervenção e construção nas zonas de preservação, com a função de harmonizar as intervenções em áreas históricas e/ou novas construções com o patrimônio existente e a paisagem urbana local (PPHAT - Lei n. 4.682). Com o tombamento, em 2011, pelo IPHAN, esses critérios foram reforçados.

A lei prevê a proteção do "patrimônio histórico arquitetônico turístico" de Jaguarão, considerando o turismo quase um valor em si mesmo. A ativação patrimonial apresenta um cenário complexo. Atualmente, adquiriu outra dimensão, a do consumo. Como resultado, pode-se ter a espetacularização, redução extrema da polissemia dos elementos, perda dos significados, gratificação imediata e superficial (PRATS, 2005, p.22). Nesse sentido, ainda que seja importante promover o turismo, ele não pode ser um valor em si mesmo, mas uma consequência de algo de interesse que a localidade possui e pode oferecer.

No ano de 2008, foi realizada uma pesquisa pelo Serviço Brasileiro de Apoio às Micro e Pequenas Empresas do Rio Grande do Sul (SEBRAERS) em parceria com a Secretaria de Cultura de Jaguarão e como apoio da Associação Comercial sobre o turismo no município. Nessa pesquisa, foi constatado que $51 \%$ dos entrevistados procuraram conhecer a cidade de Jaguarão. Quando consultados sobre o que eles mais gostaram, 53\% dos entrevistados responderam que foi a arquitetura da cidade, a beleza natural do Rio Jaguarão e a hospitalidade do povo. Também foram perguntados quais tipos de atividades de turismo, lazer ou culturais gostariam de encontrar em Jaguarão e as mais mencionadas foram, 
respectivamente, passeios turísticos, melhores restaurantes, teatro e passeios de barco pelo Rio Jaguarão (SEBRAE, 2008).

Jaguarão possui, em parceria com o SEBRAE, trabalhos como a mencionada pesquisa com os turistas, trabalhos com o trade de turismo na cidade e dois roteiros que podem ser realizados a pé: o Roteiro das Portas e o Roteiro Arquitetônico (CUSTÓDIO, 2009). Porém, observa-se a necessidade de implementar mais políticas envolvendo a comunidade e direcionadas para o turismo, como, por exemplo, a implementação efetiva do Conselho Municipal do Turismo e a criação de um Plano de Desenvolvimento do Turismo. Para ambos, é possível (e desejável) realizar uma parceria com a Universidade instalada no município.

A Universidade Federal do Pampa, por intermédio dos Cursos de Gestão de Turismo e Licenciatura em História, tem desenvolvido alguns projetos, levantando as possibilidades do uso do patrimônio para a comunidade e para o desenvolvimento do turismo local. Dentre esses trabalhos, há um projeto que vem sendo desenvolvido na perspectiva da Educação Patrimonial, que tem procurado pesquisar a história local, seus bens patrimoniais e significados para trabalhar em sala de aula junto aos alunos de Ensino Fundamental, Médio e Educação de Jovens e Adultos - EJA. ${ }^{6}$

Há projetos no Curso de Gestão em Turismo voltados para temas específicos do patrimônio local, propondo estudos, interpretações e roteiros turístico-patrimoniais. Destaca-se os trabalhos de Carvalho (2011) sobre "Os ornamentos nos casarões de Jaguarão: Contribuição para um roteiro Turístico", uma proposta que contribui para uma maior riqueza às informações já existentes; o de Berrutti (2011) "Arte Cemiterial e Tumular: Cemitério Das Irmandades de Jaguarão", que propõe um roteiro pelo cemitério mais antigo da cidade; o trabalho de Mello (2012) "Proposta de estudo para a elaboração de um city tour na cidade de Jaguarão", que busca criar um roteiro noturno pelos principais pontos turísticos da cidade, envolve não apenas as edificações, mas espaços simbólicos e gastronomia local; ainda se pode citar o projeto de Rodrigues (2011) "Contribuição de passeios turísticos de carruagem

\footnotetext{
6 Trata-se do Programa de Iniciação à Docência (PIBID-CAPES) do Curso de História. O projeto vem sendo desenvolvido em uma escola do município, o Instituto Estadual de Educação Espírito Santo.
} 
para a consolidação de roteiros patrimoniais", que visa realizar passeios de carruagem pelo centro histórico de Jaguarão.

Ainda no âmbito da Universidade, pode-se mencionar a criação do Centro de Interpretação Pampa, espaço cultural que funcionará nas ruínas de uma antiga enfermaria militar localizada no Cerro da Pólvora, construída em 1883. A criação do Centro, uma parceria entre a prefeitura e a Universidade, prevê a reabilitação do espaço para abrigar um espaço museológico. Segundo o arquiteto, o tema central que será tratado no Centro é a singularidade da paisagem física e humana do chamado Pampa. O edifício da antiga enfermaria será recuperado, mantendo seu aspecto de ruína, bem como serão acrescidas novas instalações (FERRAZ, 2011).

A criação do Centro gera uma expectativa na cidade de que, para além dos usos turísticos, o espaço seja utilizado em benefício da população, seja por seus usos culturais, seja em função da requalificação e urbanização da área do entorno, considerada patrimonial por seu caráter histórico e paisagístico.

Pode-se questionar se a patrimonialização - tornar determinados bens patrimônio, no caso de Jaguarão quase a cidade inteira representa um entrave ou incentivo para o desenvolvimento local? A resposta nunca é simples, envolve diversos atores e pontos de vista, além de alguns impasses. O desafio está em conciliar a preservação do patrimônio com a adequação das cidades para os usos contemporâneos, garantindo qualidade de vida à população. Um planejamento é a ferramenta mais eficaz, não apenas envolvendo as áreas patrimonializadas, mas todo o espaço urbano. O incentivo ao turismo cultural também desempenha um papel decisivo ao promover o patrimônio como um atrativo e, ao mesmo tempo, trazer investimentos que possam ser utilizados na melhoria dos lugares. Sempre haverá o risco, que deve ser assumido e enfrentado, da espetacularização do patrimônio, da gentrificação, da exclusão das populações locais e da real falta de identidade entre o patrimônio e a comunidade, sobretudo, quando essa é excluída dos debates e dos processos de patrimonialização.

\section{REFERÊNCIAS}


BAHL, Miguel. Viagens e Roteiros Turístico. Curitiba: Protexto, 2004.

BRASIL. Ministério do Turismo. Turismo Cultural: orientações básicas. Ministério do Turismo, Secretaria Nacional de Políticas de Turismo, Departamento de Estruturação, Articulação e Ordenamento Turístico, Coordenação-Geral de Segmentação. 3. ed. Brasília: Ministério do Turismo, 2010.

BERRUTTI, Alice. Arte Cemiterial e Tumular: Cemitério Das Irmandades de Jaguarão. Projeto Aplicado I. Curso de Gestão em Turismo, UNIPAMPA, Jaguarão, 2011.

CARRIÓN, Fernando (ed.). Centros Históricos de América Latina y el Caribe. UNESCO/FLACSO: Ecuador, 2001.

CARVALHO, Leila Meneses. Os ornamentos nos casarões de Jaguarão: Contribuição para um roteiro Turístico. Projeto Aplicado I. Curso de Gestão em Turismo, UNIPAMPA, Jaguarão, 2011.

CUSTÓDIO, Luiz Antônio. Roteiros de Arquitetura da Costa Doce. Rio Grande do Sul. Porto Alegre: Editora Sebrae, 2009.

DE MELLO, Hilda Mara Gonçalves. Proposta de estudo para a elaboração de um city tour na cidade de Jaguarão. Trabalho de Conclusão de Curso. Curso de Gestão em Turismo, UNIPAMPA, Jaguarão, 2012.

Dossiê de Tombamento Conjunto histórico e paisagístico de Jaguarão RS. Org. Anna Finger. Revisão: Ana Lúcia Meira. IPHAN, 2010.

CORIOLANO, Luzia Neide M. T. A contribuição do turismo ao Desenvolvimento local. In: PORTUGUEZ, Anderson Pereira; SEABRA, Giovanni de Farias; QUEIROZ, Odaléia Telles M. M. (Org.). Turismo, espaço e estratégias de desenvolvimento local. João Pessoa: Editora Universitária da UFPB, 2012.

FERRAZ, Marcelo. Um Centro de Referência para o Pampa. In: Arqtexto $15,2011$. 
FRANCO, Sérgio da Costa. Origens de Jaguarão (1790-1833). Caxias do Sul: Ed. UCS, 1980.

GUTMAN, Margarita Del monumento aislado a la monumentalidad:. p.p. 95-106. In:_CARRIÓN, Fernando (ed.) Centros Históricos de América Latina y e/ Caribe. UNESCO/FLACSO: Ecuador, 2001.

BALLART HERNÁNDEZ, Josep; TRESSERAS, Jordi Juan i. Gestión del património cultural. 3a ed. Barcelona: Editorial Ariel, 2007.

MAGALHÃES, Cláudia Freitas, Diretrizes para o Turismo Sustentável em municípios. São Paulo: Roca, 2002.

MARTINS, Roberto Duarte. A ocupação do espaço na fronteira BrasilUruguai: a construção da cidade de Jaguarão. Tese. (Arquitetura). Escola Técnica d' Arquitetura Universidat Politécnica de Cataluña. Barcelona: 2001.

MIRANDA, Wilson Marcelino. Arquitetura e urbanismo na fronteira Brasil/ Uruguai: o espaço comercial construído em Jaguarão/ Rio Branco (1800-1940). Tese (Arquitetura). Faculdade de Arquitetura. Universidade Federal de Pelotas, 2002.

MOLETTA, Vânia Florentino. Turismo Cultural. 2.ed. Porto Alegre: SEBRAE, 2000.

OLIVEIRA, Ana Lúcia de, SEIBT, Maurício Borges. Programa de Revitalização Integrada de Jaguarão. Pelotas: Editora Universitária UFPel, 2005.

OLIVEIRA, Ana Lúcia de, SEIBT, Maurício Borges. Projeto Jaguar: inventário do patrimônio arquitetônico da cidade de Jaguarão. Pelotas: Ed. UFPel, 1988.

PRATS, Lorenç. Concepto y gestión del patrimonio local. Cuadernos de Antropología Social No 21, pp. 17-35, 2005. 
La viabilidad turística del patrimonio. PASOS Revista de Turismo y Patrimonio Cultural, vol.9, num.2, abril, pp.249-264. Universidad de La Laguna. El Sauzal (Tenerife) España, 2011.

RODRIGUES, Mabel de Faria. Mabel de Farias Rodrigues. Contribuição de passeios turísticos de carruagem para a consolidação de roteiros patrimoniais. Projeto Aplicado I. Curso de Gestão em Turismo, UNIPAMPA, Jaguarão, 2011.

SANTOS, Carlos Alberto Ávila. Ecletismo na Fronteira Meridional do Brasil: 1870-1931. Tese (Arquitetura). Universidade Federal da Bahia, 2007.

SANTOS, Milton. Por uma outra Globalização. Do pensamento único à consciência universal. Rio de Janeiro Record, 2000.

SEBRAE. Pesquisa sobre turismo em Jaguarão/RS. Projeto: APL de Turismo na Costa Doce. 2008.

SFORZI, F. La economía marshalliana para explicar el desarrollo. In: Manual de Desarrollo Local. FERMín, Rodríguez Gutiérrez. Coimbra: Gijón Ediciones Trea, S. L., 1999.

SILVA, Teodomiro Fernandes da. Cooperação interempresarial: Novas estratégias empresariais para pequenas empresas no processo de desenvolvimento local e do turismo. Disponível em:

<http://www.periodicodeturismo.com.br/site/artigo/pdf/rede.PDF >. Acesso em 20 jan/2013.

Submetido em 10/06/2013.

Aprovado em $27 / 10 / 2015$.

Sobre as autoras Juliane Conceição Primon Serres

Professora do Departamento de Museologia, Conservação e Restauro e do Programa de Pós-Graduação em Memória Social e Patrimônio Cultural da Universidade Federal de Pelotas. 
O Patrimônio Local como um fator de desenvolvimento: potencialidades turísticas de Jaguarão - RS

Endereço Profissional: Rua Lobo da Costa 1877. 96010-150 - Pelotas, RS, Brasil. E-mail: julianeserres@gmail.com.br

\section{Juliana Rose Jasper}

Mestre em Turismo. Professora Universidade Federal do Pampa - UNIPAMPA Endereço:

E-mail: 